\title{
Inertia Emulation Control Strategy for VSC-HVDC Transmission Systems
}

\author{
Jiebei Zhu, Campbell D. Booth, Grain P. Adam, Andrew J. Roscoe, Chris G. Bright
}

\begin{abstract}
There is concern that the levels of inertia in power systems may decrease in future, due to increased levels of energy being provided from renewable sources, which typically have little or no inertia. Voltage Source Converters (VSC) used in high voltage direct current (HVDC) transmission applications are often deliberately controlled in order to de-couple transients to prevent propagation of instability between interconnected systems. However, this can deny much needed support during transients that would otherwise be available from system inertia provided by rotating plant.

This paper proposes a novel VSC-HVDC control system termed "INEC" (INertia Emulation Control) which enables a VSC HVDC system to provide support that emulates the inertia of a synchronous generator (SG). The energy to do so comes from the capacitance of the HVDC connection, which may be augmented by the installation of additional capacitance. This paper indicates that the proposed INEC system allows a VSC-HVDC system with a fixed capacitance to emulate a wide range of inertia constants $(H)$ by specifying the amount of permissible DC voltage variation. The proposed INEC scheme has been demonstrated through simulations, and its performance is evaluated for transients that include faults and also changes in load.
\end{abstract}

Index Terms-Frequency response, HVDC converters, HVDC transmission control.

\section{INTRODUCTION}

$\mathrm{T}$ HERE is now an intensive focus on renewable energy development as a solution to the world's energy needs and to reduce carbon emissions. The 2009 European Union Renewable Energy Directive, has a target of generating over $32 \%$ total power from renewable by 2030 , with a target of $100 \%$ by 2050 [1]. In order to facilitate renewable generation connection, the UK transmission system operators are recommending that after 2014 , there should be an increase in the power in-feed loss limit (i.e., the amount of generation can be lost in a single event without causing undue system disturbances) from $1320 \mathrm{MW}$ to $1800 \mathrm{MW}$. This will cater for larger capacity units and installations, without significantly affecting AC system stability [2]. With such an increased power in-feed loss limit, if a large power plant trips, the system frequency is at greater risk of falling to an unacceptable level before frequency response control systems can mitigate the situation. Large system inertia can help stabilize frequency and give ample opportunity for control systems to act.

At present, many renewable generators are connected via power electronics, especially DC sources such as PV. Power electronics effectively decouples the generators from the system and prevents the kinetic energy in the inertia of the renewable power sources from mitigating system transients. There is evidence of a decrease in system inertia on the eastern interconnector in the United States during a period of more than 10 years [5] and this is believed to be due to the increasing connection of renewable energy sources. Inevitably, reduced inertia presents a greater risk of instability requiring mitigation such as changes to control systems, greater amounts of spinning reserve, and more frequent starting of generation installed to support the system.

In an attempt to address this issue, several inertia emulation control strategies for wind power generators have been proposed [3], [4], [6], [8]. These strategies enable wind power generators to contribute inertia during AC grid disturbances. The authors in [3] studied the dynamic contribution of doublyfed induction generators (DFIG) to provide an inertial response. However, the authors stated that DFIG turbines may stall if excessive energy is drawn from the rotor. Ref [4] proposes a control scheme for fully rated, converter-interfaced, permanent magnet synchronous generator (PMSG) wind generators that can provide frequency support/control capability. This is achieved by controlling the inverter output power according to the rate of change in grid frequency. The disadvantage with this scheme is that the recovery of the rotor speed can be difficult after a deceleration of the machine rotor.

HVDC transmission systems are accepted as the solution for connecting distant offshore wind farms [7]. However, existing HVDC converters also decouple the kinetic energy that may be available "beyond" the terminals of the DC system. The authors in [6] propose a coordinated control strategy for wind farms connected via line-commutated-converter (LCC) HVDC links. This strategy allows such wind farms to participate in inertial response and primary frequency control. The control strategy uses the time derivative of the grid frequency to adjust the delivered power from the wind farm via the LCC-HVDC. This in turn adjusts the blade angles of the wind turbines to increase or decrease the power captured from the wind. Nevertheless, this disadvantage is considered to be similar to the problems associated with [3][4][8], i.e. the risk of stalling wind turbines and the consequent difficulty of recovering rotor speed.

This paper presents an inertia emulation control (INEC) strategy that uses the energy stored in the DC link capacitors of the VSC-HVDC systems to emulate inertia. This supports the $\mathrm{AC}$ network during and following disturbances, with minimal impact on the systems connected beyond the terminals of the HVDC system. This can be realized by modifying the HVDC control systems. The proposed strategy is capable of emulating a wide range of inertia time constants $\mathrm{H}_{\mathrm{VSC}}$ using relatively small constant capacitances connected to the DC circuit. 


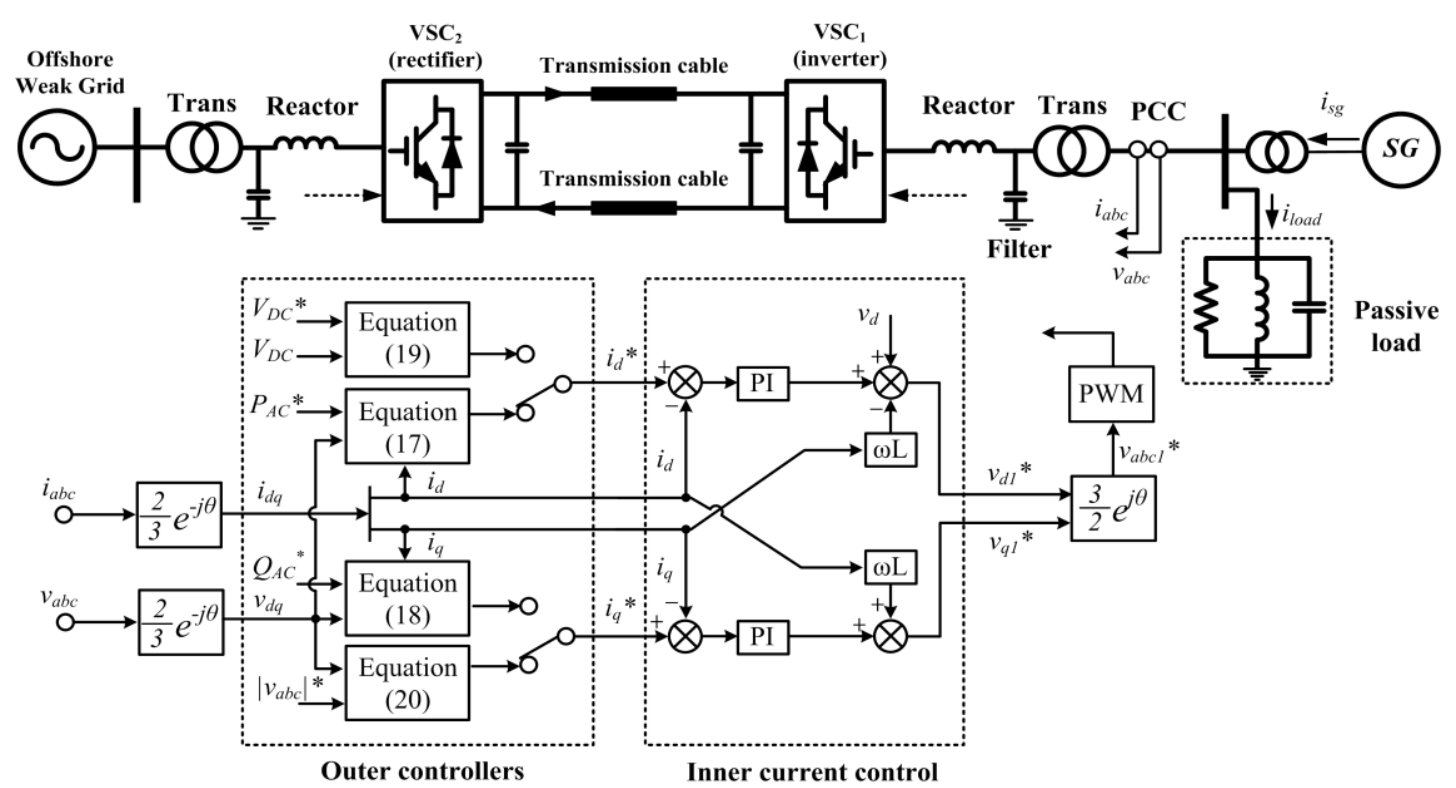

Fig.1. A Single-line diagram of VSC-HVDC transmission system, with the conventional control system

Additionally, the proposed strategy does not rely on $d f / d t$ measurement, unlike the methods reported in [3][4][6]. Therefore it will be less sensitive to any potential noise amplification caused by $d f / d t$ measurement, which in turn may cause control system instability. Moreover, the INEC acts to isolate one $\mathrm{AC}$ power system from the consequences of frequency disturbance on another $\mathrm{AC}$ power system by only using the electro-static energy in the DC link capacitors plus and the comparatively smaller capacitance of the DC circuit. Simulations using a point-to-point VSC-HVDC system connecting two AC networks have demonstrated the proposed INEC strategy. The model comprises a relatively weak power system with a DC connection to an offshore wind farm using DFIGs.

\section{SYNCHRONOUS MACHINE INERTIA}

In power systems, a difference between generation and demand will result in changes in system frequency which will be counteracted initially by the mechanical inertia and then by the governor action of prime movers. Reference [9] defines a fictitious "inertial center" for a large-scale power system, which has a mean angular speed $\bar{\omega}$ for all electrical machines in the system, and [9] derives the following equation:

$$
\frac{d \bar{\omega}}{d t}=-\frac{\Delta P}{2 \sum H}
$$

Equation (1) indicates that for a certain power imbalance $\Delta \mathrm{P}$ between generation and load, the aggregate inertia $\Sigma \mathrm{H}$ of a power system determines the mean change in network angular speed (i.e. acceleration or deceleration). A higher aggregate inertia reduces the rate of change in angular speed, leading to an increase in the overall stability of the power system.

\section{VSC-HVDC SYSTEM AND CONTROL}

Fig.1 illustrates a point-to-point VSC-HVDC system with converter station $\mathrm{VSC}_{1}$ regulating $\mathrm{DC}$ voltage and reactive power, with $\mathrm{VSC}_{2}$ controlling active and reactive power. $\mathrm{VSC}_{2}$ is connected to a weak offshore grid through interfacing reactors, AC side filters and a coupling transformer. The VSC-HVDC system offers a degree of control freedom by allowing independent control of active and reactive power. As shown in Fig. 1, the active power can be controlled either directly using a power set-point or indirectly by regulating the DC voltage. The reactive power is controlled either directly using a reactive power set-point, or by regulating the $\mathrm{AC}$ voltage magnitude at the point of common coupling (PCC). The choice of control mode depends on the nature of the specific application. However, at least one of the VSC stations must be assigned to control the DC voltage. The details of the inner current control loop and various outer controllers for VSC-HVDC, as shown in Fig.1, are described in the following sub-sections.

\section{A. Inner current controller}

Fig. 2 shows a schematic diagram of a three-phase VSC connected to an $\mathrm{AC}$ grid with three-phase voltage $v_{a b c}$ at the PCC. $v_{a b c l}$ represents the three-phase voltage generated at the converter terminals. The AC-side dynamics of the converter can be expressed by the following equation:

$$
v_{a b c 1}-v_{a b c}=L \frac{d i_{a b c}}{d t}+R i_{a b c}
$$

In equation (2), $i_{a b c}$ represents the three-phase currents flowing through interfacing reactor and coupling transformer,

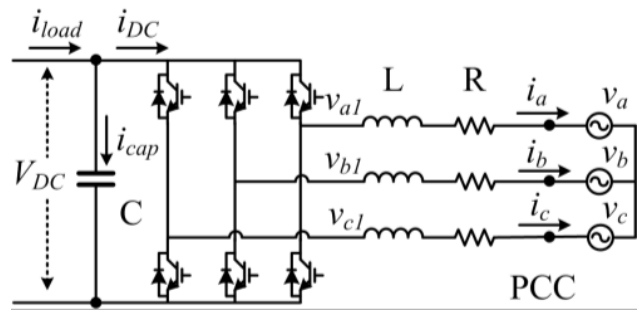

Fig.2. Three-phase VSC equivalent model

This is a postprint of a paper submitted to and accepted for publication in IEEE Transactions on Power Systems [http://dx.doi.org/10.1109/TPWRS.2012.2213101] and is subject to IEEE copyright. 
and $\mathrm{L}$ and $\mathrm{R}$ are the equivalent combined inductance and resistance of the phase reactor and transformer.

A synchronous $d-q$ reference approach is conventionally employed to facilitate VSC-HVDC control [10][11]. The positive-sequence three-phase voltages $v_{a b c}$ and currents $i_{a b c}$ measured at the PCC are transformed to $d-q$ components $v_{d q}$ and $i_{d q}$ via the Park Transformation [12]:

$$
\begin{aligned}
& v_{d q}=v_{d}+j v_{q}=\frac{2}{3} j e^{-j \omega t}\left(v_{a}+e^{j \frac{2}{3} \pi} v_{b}+e^{-j \frac{2}{3} \pi} v_{c}\right) \\
& i_{d q}=i_{d}+j i_{q}=\frac{2}{3} j e^{-j \omega t}\left(i_{a}+e^{j \frac{2}{3} \pi} i_{b}+e^{-j \frac{2}{3} \pi} i_{c}\right)
\end{aligned}
$$

A phase-locked-loop (PLL) block is used to synchronize the HVDC converter to the grid voltage at the PCC and to align the voltage vector of the grid with the d-axis (when the network voltage at the PCC remains constant and balanced, $v_{q}=0$ ). In the synchronous d-q reference frame, the dynamics of the VSC station in (4) can be expressed as:

$$
\begin{gathered}
v_{d 1}=L \frac{d i_{d}}{d t}+R i_{d}-\omega L i_{q}+v_{d} \\
v_{q 1}=L \frac{d i_{q}}{d t}+R i_{q}+\omega L i_{d}
\end{gathered}
$$

where $v_{d l}$ and $v_{q l}$ are the d-axis and q-axis converter side voltage vectors.

In order to track the reference currents $i_{d}{ }^{*}$ and $i_{q}{ }^{*}$, the inner current control uses proportional-integral (PI) controllers with feedback to regulate the current vectors $i_{d}$ and $i_{q}$. Therefore, the VSC voltage vector references $v_{d l}{ }^{*}$ and $v_{q l}{ }^{*}$ for VSC are computed as follows:

$$
\begin{gathered}
v_{d 1}^{*}=\left(k_{p}+\frac{k_{i}}{s}\right)\left(i_{d}^{*}-i_{d}\right)+R i_{d}-\omega L i_{q}+v_{d} \\
v_{q 1}^{*}=\left(k_{p}+\frac{k_{i}}{S}\right)\left(i_{q}^{*}-i_{q}\right)+R i_{q}+\omega L i_{d}+v_{q}
\end{gathered}
$$

The voltage vector references $v_{d l}{ }^{*}$ and $v_{q 1}{ }^{*}$ are transformed to a three-phase value $v_{a b c l}{ }^{*}$ for pulse width modulation (PWM) to produce the desired converter three-phase voltage.

The active and reactive powers that the VSC-HVDC inject into the $\mathrm{AC}$ system are expressed in the $d q$-axis as:

$$
\begin{aligned}
& P_{A C}=\frac{3}{2}\left(v_{d} i_{d}+v_{q} i_{q}\right)=\frac{3}{2} v_{d} i_{d} \\
& Q_{A C}=\frac{3}{2}\left(v_{q} i_{d}-v_{d} i_{q}\right)=-\frac{3}{2} v_{d} i_{q}
\end{aligned}
$$

In (9) and (10), the decoupled control of active and reactive powers is achieved. During steady state, active and reactive powers are proportional to $i_{d}$ and $i_{q}$ respectively.

\section{B. Outer controllers}

The outer controllers are shown at the left hand side of the cascaded control system in Fig.1. In order to ensure stability, they must be slower-acting than the inner current control loops introduced in the previous section [10].

The active power controller produces the $d$-axis current reference $i_{d}{ }^{*}$ for the inner current controller according to the active power reference $P_{A C}$ *

$$
i_{d}^{*}=\frac{P_{A C}^{*}}{\frac{3}{2} v_{d}}
$$

In a similar way, the reactive power controller calculates the $q$-axis current reference $i_{q}{ }^{*}$ from the reactive power reference $Q_{A C}^{*}$ according to:

$$
i_{q}^{*}=\frac{Q_{A C}^{*}}{\frac{3}{2} v_{d}}
$$

Assuming the VSC is lossless, the active powers of the AC and DC sides are obtained by the following:

$$
i_{D C}=\frac{\frac{3}{2} v_{d} \cdot i_{d}}{V_{D C}}
$$

where $V_{\mathrm{DC}}$ and $i_{\mathrm{DC}}$ refer to the $\mathrm{DC}$ side voltage and current.

The charging and discharging of the DC capacitor in Fig.2 can be expressed using:

$$
C \cdot \frac{d V_{D C}}{d t}=i_{D C}-i_{\text {load }}
$$

The combination of (13) and (14) gives the $d$-axis current reference $i_{d}{ }^{*}$, which represents the output of the DC voltage controller:

$$
i_{d}^{*}=\frac{V_{D C}^{*}}{\frac{3}{2} v_{d}}\left(C \frac{d V_{D C}}{d t}+i_{\text {load }}\right)
$$

For the control of the AC voltage amplitude at the PCC, the magnitude of the voltage drop across the reactor and transformer impedance $R+j \omega L$ is approximated as:

$$
\Delta v=\left|v_{a b c c}\right|-\left|v_{a b c}\right|=\frac{R P_{A C}+\omega L Q_{A C}}{v_{d}} \approx \frac{\omega L}{v_{d}} Q_{A C}
$$

where $\left|v_{a b c 1}\right|=\sqrt{v_{d 1}^{2}+v_{q 1}^{2}}$ and $\left|v_{a b c}\right|=\sqrt{v_{d}^{2}+v_{q}^{2}}$.

In the reactor and the transformer, $\omega L » R$, thus the voltage amplitude drop only depends on the reactive power flow $Q_{A C}$. The reactive component $q$-axis current $i_{q}{ }^{*}$ is thus calculated in the AC voltage amplitude controller, from the error between the PCC voltage amplitude set point $\left|v_{a b c}{ }^{*}\right|$ and the actual voltage amplitude $\left|v_{a b c}\right|$.

With PI controllers, the equations of active power, reactive power, $\mathrm{DC}$ voltage and $\mathrm{AC}$ voltage controllers in the s-domain are as follows:

$$
\begin{aligned}
& i_{d}^{*}=\frac{P_{A C}^{*}}{\frac{3}{2} V_{d}}+\left(k_{p}+\frac{k_{i}}{S}\right)\left(P_{A C}^{*}-P_{A C}\right) \\
& i_{q}^{*}=\frac{Q_{A C}^{*}}{\frac{3}{2} V_{d}}+\left(k_{p}+\frac{k_{i}}{S}\right)\left(Q_{A C}^{*}-Q_{A C}\right) \\
& i_{d}^{*}=\left(k_{p}+\frac{k_{i}}{S}\right)\left(V_{D C}^{*}-V_{D C}\right) \\
& i_{q}^{*}=\left(k_{p}+\frac{k_{i}}{s}\right)\left(\left|v_{a b c}^{*}\right|-\left|v_{a b c}\right|\right)
\end{aligned}
$$

VSC-HVDC converters do not normally possess any overload capability [10]. Severe network disturbances such as AC system faults will stress the converter switches with overcurrent. Therefore, current limitation must be included in both the outer controllers and the inner current control schemes to protect against overcurrent.

This is a postprint of a paper submitted to and accepted for publication in IEEE Transactions on Power Systems [http://dx.doi.org/10.1109/TPWRS.2012.2213101] and is subject to IEEE copyright. 


\section{VSC-HVDC INERTIA EMULATION CONTROL}

The proposed INEC uses stored energy in the HVDC DC capacitors to provide an inertial response, which can not only support frequency stability but also contribute to primary frequency control of the supplied AC network. Energy for the INEC is provided solely from DC link capacitors by using the converters to control the DC link voltage. The INEC algorithm contains the following four steps:

1) Machine inertia time contant versus capactor time constant;

2) Capacitor DC voltage and emulated inertia time constant;

3) VSC-HVDC INEC design loop;

4) Frequency change versus DC voltage change.

\section{A. Machine inertia time constant vs. capacitor time constant}

The inertia constant $\mathrm{H}$, which determines the response of SG angular speed to any changes in input power, can be expressed by:

$$
H=\frac{W_{K}}{S_{M}}=\frac{\frac{1}{2} J \omega^{2}}{S_{M}}
$$

where $\mathrm{W}_{\mathrm{K}}$ represents kinetic energy stored in the rotating mass of the machine (MVA.sec), J refers to the moment of inertia $\left(\mathrm{kg} \cdot \mathrm{m}^{2}\right)$ and $\mathrm{S}_{\mathrm{M}}$ is the generator rating (MVA).

Capacitors are used in VSCs for DC voltage stability and filtering [10]. The size of the DC capacitors is characterized by a capacitor time constant $\tau$, given in (22):

$$
\tau=\frac{W_{E}}{S_{V S C}}=\frac{\frac{1}{2} C N V_{D C}^{2}}{S_{V S C}}
$$

where $\mathrm{W}_{\mathrm{E}}$ represents the electro-static energy stored in the capacitor, $\mathrm{S}_{\mathrm{VSC}}$ represents the VSC rated power capability, $\mathrm{C}$ is the capacitance of a single DC capacitor and $N$ is the total number of capacitors installed on the DC link (in the example of Fig.1, there are two capacitors in total for the three-level neutral-point clamped VSC, therefore $N=2$ ).

To some extent, the electro-static energy stored in DC capacitors is similar to the mechanical energy stored in the inertia of SGs, as both the angular speed $\omega$ of the SGs, and DC voltage $V_{\mathrm{DC}}$ of the VSC-HVDC capacitors are squared in (21) and (22) respectively.

\section{B. Capacitor DC voltage and emulated inertia time constant}

The equation of the machine angular motion is given in (23):

$$
\frac{2 H}{f_{0}} \cdot \frac{d f}{d t}=P_{M}-P_{E}=\Delta P_{1} \quad(p u)
$$

where $\mathrm{H}$ is the inertia time constant in sec, $\mathrm{f}_{0}$ is the nominal frequency in $\mathrm{Hz}, \mathrm{P}_{\mathrm{M}}$ is the mechanical power in pu, $\mathrm{P}_{\mathrm{E}}$ is the electrical power in pu and $\Delta \mathrm{P}_{1}$ is the kinetic power absorbed by or released from the inertia of the machine during a speed change (in pu).

In order to equate the available power of the DC capacitors to that of an electrical machine, the capacitor dynamics (in terms of DC voltage and output power) are presented in equation (24):

This is a postprint of a paper submitted to and accepted for publication in IEEE Transactions on Power Systems [http://dx.doi.org/10.1109/TPWRS.2012.2213101] and is subject to IEEE copyright.

$$
\frac{N C V_{D C}}{S_{V S C}} \cdot \frac{d V_{D C}}{d t}=P_{\text {in }}-P_{\text {out }}=\Delta P_{2} \quad(p u)
$$

In equation (24), $\mathrm{N}$ represents the total number of capacitors (two in this case), $S_{V S C}$ represents the VSC rated power capability in watts, $P_{\text {in }}$ is VSC power input to the two capacitors in $\mathrm{pu}, P_{\text {out }}$ is the VSC power output in pu, and $\Delta P_{2}$ is the dynamic electro-static power stored or released across both capacitors in pu.

Equation (24) indicates that any variation in DC voltage changes the stored energy in the capacitors. This energy is charged or discharged by varying the DC voltage according to the DC voltage controller as discussed in Section III. Due to the low resistance of the DC cables, the DC voltage difference between the rectifier and inverter is negligible. For this reason, the DC voltages at the rectifier and inverter are assumed to be the same for the purposes of this analysis.

A further task is to assign a specific emulated "inertia" constant $\mathrm{H}_{\mathrm{VSC}}$ to the HVDC system. Equating the SG power variation $\Delta P_{1}$ in (23) with capacitor power $\Delta P_{2}$ in (24) yields:

$$
\frac{2 H_{V S C}}{f_{0}} \cdot \frac{d f}{d t}=\frac{N C V_{D C}}{S_{V S C}} \cdot \frac{d V_{D C}}{d t}
$$

Integrating both sides of (25) yields (26) below. This process cancels $d f / d t$ and $d V_{D C} / d t$ on the two sides into (27):

$$
\begin{gathered}
\int \frac{2 H_{V S C}}{f_{0}} \cdot d f=\int \frac{N C V_{D C}}{S_{V S C}} \cdot d V_{D C} \\
\frac{2 H_{V S C} \cdot f}{f_{0}}=\frac{N C V_{D C}^{2}}{2 S_{V S C}}+K_{1}
\end{gathered}
$$

The constant $\mathrm{K}_{1}$ is the constant of integration which is calculated according to the specified values of $\mathrm{H}_{\mathrm{VSC}}$, total combined DC capacitance $\mathrm{NC}$, the nominal DC voltage $\mathrm{V}_{\mathrm{DC} 0}$ and the converter power rating $\mathrm{S}_{\mathrm{VSC}}$. This is shown in (28):

$$
K_{1}=\frac{2 H_{V S C} \cdot f_{0}}{f_{0}}-\frac{N C V_{D C 0}^{2}}{2 S_{V S C}}=2 H_{V S C}-\frac{N C V_{D C 0}^{2}}{2 S_{V S C}}
$$

The full INEC equation can then be expressed in (29):

$$
\frac{2 H_{V S C} \cdot f}{f_{0}}=\frac{N C V_{D C}^{2}}{2 S_{V S C}}+\left(\frac{2 H_{V S C} \cdot f_{0}}{f_{0}}-\frac{N C V_{D C 0}^{2}}{2 S_{V S C}}\right)
$$

Equation (29) can also be written in another format, shown in (32), that can be used to evaluate the influence of DC voltage change $\Delta V_{D C}$ on the VSC-HVDC emulated inertia time

$$
\begin{gathered}
2 H_{V S C} \cdot \frac{f-f_{0}}{f_{0}}=\frac{N C}{2 S_{V S C}}\left(V_{D C}^{2}-V_{D C 0}^{2}\right) \\
2 H_{V S C} \cdot \frac{\Delta f}{f_{0}}=\frac{N C \cdot V_{D C 0}^{2}}{2 S_{V S C}} \cdot\left[\left(\frac{\Delta V_{D C}}{V_{D C 0}}+1\right)^{2}-1\right] \\
H_{V S C}=\frac{\frac{1}{2} \cdot \frac{N C \cdot V_{D C 0}^{2}}{S_{V S C}}\left[\left(\frac{\Delta V_{D C}}{V_{D C 0}}+1\right)^{2}-1\right]}{2 \cdot \frac{\Delta f}{f_{0}}}
\end{gathered}
$$

Equation (32) implies that to emulate a specific inertia time constant $\mathrm{H}_{\mathrm{VSC}}$, the DC voltage level in VSC-HVDC link must vary according to the $\mathrm{AC}$ network frequency, although the variation will be non-linear. A large value of $H_{V S C}$ will require constant for a given change of network frequency $\Delta f$ : 


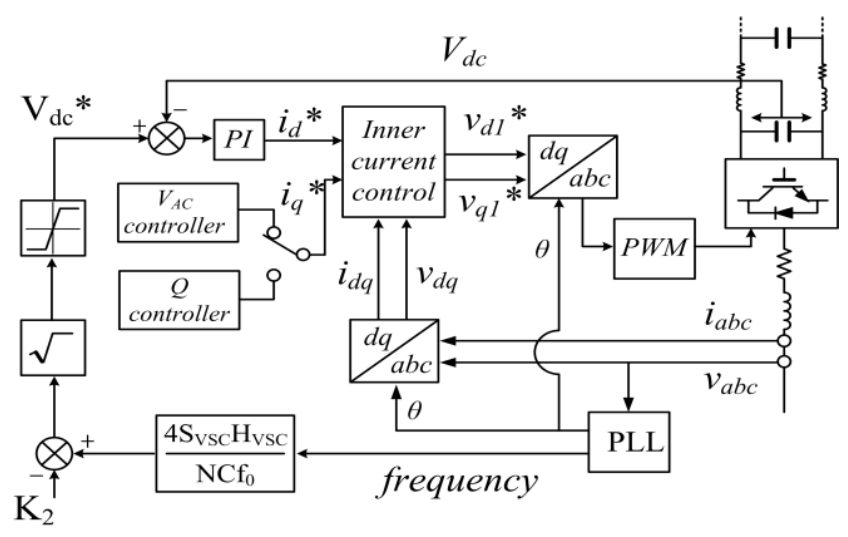

Fig.3. Proposed inertia emulation control system for VSC-HVDC

a correspondingly large variation in $\mathrm{DC}$ voltage and this must be considered in the design of the VSC-HVDC system.

\section{VSC-HVDC INertia Emulation Control loop}

As already stated, the DC voltage of the VSC-HVDC must vary according to $\mathrm{AC}$ network frequency. Equation (27) is transformed to (33) to facilitate DC voltage control:

$$
V_{D C}^{*}=\sqrt{\frac{4 S_{V S C} H_{V S C}}{N C f_{0}} \cdot f-K_{2}}
$$

Where $K_{2}=\frac{4 S_{V S C} H_{V S C}}{N C}-V_{D C 0}^{2}$.

Fig.3 illustrates the design of the INEC. The DC voltage reference $V_{D C}{ }^{*}$ varies with AC network frequency $f$. The prevailing $\mathrm{AC}$ network frequency, which is estimated by the PLL, is used to compute the DC voltage reference through the gains and square root operations based on (33). Other variables, including the initial integration state factor $\mathrm{K}_{2}$, the VSC rated power capability $\mathrm{S}_{\mathrm{VSC}}$ and specified inertia time constant $\mathrm{H}_{\mathrm{VSC}}$ are all included in the INEC loops.

The DC voltage reference should be limited within upper and lower constraints, for example $\pm 15 \%$ of nominal DC voltage although the exact figures would depend on insulation requirements, current ratings and PWM functionality.

Unlike the proposed inertia emulation control in [3][4][6], the implementation of INEC in (33) avoids the processing of frequency differential terms $d f / d t$ with the consequent risk of measurement noise threatening stability especially in response to step transients [13].

The INEC strategy has the potential for implementation in multi-terminal HVDC (MTDC) systems. In equation (33), $N$ is the total number of capacitors present in the MTDC network. With the INEC strategy, the DC slack bus voltage controller is able to make an inertial contribution to its connected AC grid. For power systems that are coupled via HVDC links, the possibility of INEC implementation is dictated by converter control that varies the DC voltage to make the energy from the DC link capacitance available to the AC system(s). In an HVDC link connecting two AC systems, it is not recommended that both terminals of the link employ INEC, as if both are attempting to dictate the $\mathrm{DC}$ voltage simultaneously, there is the potential for deterioration of DC voltage stability and DC

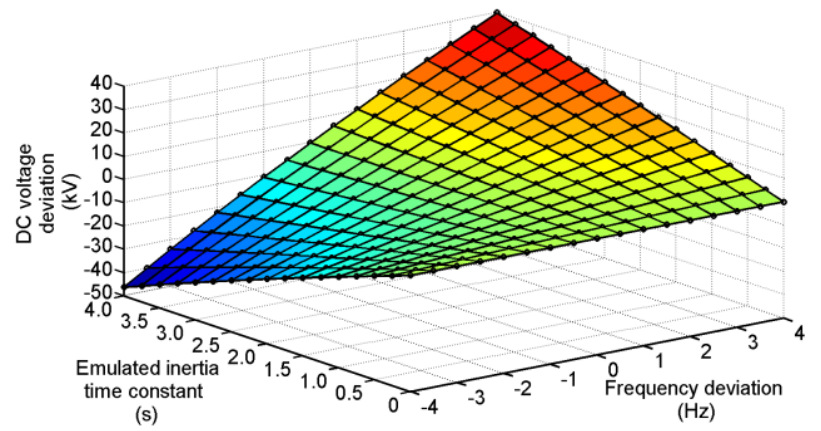

Fig.4. Three-dimensional relationship between emulated inertia, frequency and DC voltage deviations from rated value (total DC link capacitance $=2 * 7.5 \mathrm{mF}$ )

link power flow control.

\section{Frequency change vs. DC voltage change}

It is clear from the previous discussions that VSC-HVDC has the potential to emulate a wide range of inertia time constants, if its DC voltage is allowed to vary by a wide margin. A range of inertia constants from 0 s to $4 \mathrm{~s}$ along with the associated resultant DC voltage changes for specific frequency changes is plotted in Fig. 4. The maximum inertia time constant that can be provided will depend on the degree of permissible DC voltage variations, the value of DC link capacitors as shown in (32) and the converter's active power limit.

Equation (31) presents the relationship between the square of DC voltage variation and DC capacitance, which is inversely proportional in nature. Relatively large capacitors (e.g. $7.5 \mathrm{mF}$ in this paper) are used in order to lower DC voltage variations. Large DC capacitors will obviously require DC link protection; smaller values of DC capacitance could be used, with inertial responses being provided using larger DC voltage variations see section $\mathrm{V}$ for examples of the use of different capacitor values. It is important to emphasize that the scheme reported in this paper is intended to provide an "instantaneous" inertial response, and would obviously be required to be backed up by a longer term controlled response for events involving major loss of generation/transmission capacity in the supplied AC system. DC links and controllers could also be used for this purpose, with excess energy being delivered and sourced from other AC systems and/or wind farms (if available and permissible).

\section{Performance eVAluation}

The evaluation scenario as illustrated in Fig. 5 is simulated by SimpowerSystems in Matlab. A point-to-point VSC-HVDC link comprises three-phase converters $\mathrm{VSC}_{1}$ and $\mathrm{VSC}_{2}$, with parameters as presented in TABLE I. VSC 2 , which is connected to the wind farm, regulates the active and reactive power by controlling offshore grid frequency and $\mathrm{AC}$ voltage amplitude in System 2. $\mathrm{VSC}_{1}$ supplies power to System 1 at $\mathrm{B}_{1}$ which represents a relatively weak system consisting of one synchronous generator and associated loads. The fixed load $P_{L I}$ $+Q_{L 1}$ is $400 \mathrm{MW}+100 \mathrm{MVar}$, whereas the load $P_{L 2}+Q_{L 2}$ can be switched in or out and is $20 \mathrm{MW}+5 \mathrm{MVar}$. The loads in System 1 are therefore being supplied by both the synchronous

This is a postprint of a paper submitted to and accepted for publication in IEEE Transactions on Power Systems [http://dx.doi.org/10.1109/TPWRS.2012.2213101] and is subject to IEEE copyright. 


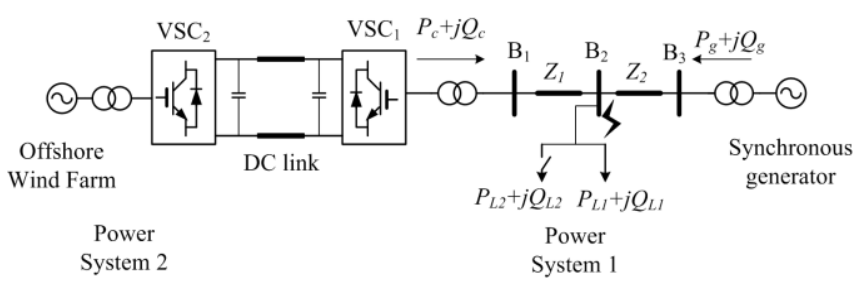

Fig.5. A single-line diagram of the simulated test system

TABLE I

PARAMETERS FOR THE VSC-HVDC LINK

\begin{tabular}{ll}
\hline \hline Item & Value \\
\hline Rated VSC power $S_{V S C}$ & $300 \mathrm{MW}$ \\
Rated VSC AC rms voltage $V_{v s c}$ & $150 \mathrm{kV}$ \\
Nominal DC voltage $V_{d c}$ & $300 \mathrm{kV}$ \\
Reactor inductance $L$ & $0.15 \mathrm{pu}$ \\
Reactor resistance $R$ & $0.005 \mathrm{pu}$ \\
DC capacitor $C_{d c}$ & $7.5 \mathrm{mF}$ \\
Total capacitor number $N$ & 2 \\
Switching frequency $f_{s w}$ & $1350 \mathrm{~Hz}$ \\
\hline Rated AC rms voltage in System 1 & $150 \mathrm{kV}$ \\
\hline \hline
\end{tabular}

TABLE II

PARAMETERS FOR SYNCHRONOUS GENERATOR

\begin{tabular}{ll}
\hline \hline Item & Value \\
\hline Rated MVA $S_{g}$ & $200 \mathrm{MVA}$ \\
Terminal Voltage $V_{g}$ & $13.8 \mathrm{kV}$ \\
Inertia time constant & $3.2 \mathrm{~s}$ \\
$x_{d}, x_{d}{ }^{\prime}, x_{d}{ }^{\prime \prime}$ & $1.305,0.296,0.252$ \\
$x_{q}, x_{q}{ }^{\prime}, x_{l}$ & $0.474,0.243,0.18$ \\
$\tau_{d}, \tau_{d},, \tau_{q}{ }^{\prime}$ & $1.01,0.053,0.1$ \\
Stator resistance $R_{s}$ & $2.8544 \mathrm{e}-3 \mathrm{pu}$ \\
Pole pairs $p$ & 32 \\
\hline Turbine permanent droop $R_{p}$ & 0.05 \\
Turbine time constant $T_{w}$ & $2.67 \mathrm{~s}$ \\
Servo-motor time constant & $0.07 \mathrm{~s}$ \\
\hline Exciter regulator gain & 300 \\
Exciter time constant & $0.001 \mathrm{~s}$ \\
\hline \hline
\end{tabular}

generator in System 1 and by System 2 via the HVDC system.

The synchronous generator (SG) is modeled using a seventh-order model with IEEE parameters [14][15] as shown in TABLE II, where the electromagnetic transients and mechanical dynamics are incorporated. To illustrate the effectiveness of the proposed INEC strategy, the simulations comprise three different situations: emulated inertia time constants $\mathrm{H}_{\mathrm{VSC}}=0$ (conventional VSC-HVDC control), $\mathrm{H}_{\mathrm{VSC}}=1 \mathrm{~s}$ and $\mathrm{H}_{\mathrm{VSC}}=3 \mathrm{~s}$, which are specified individually in the INEC design in Fig.3.

Two scenarios are considered:

-- Sudden load changes using $P_{L 2}+j Q_{L 2}$ in System 1

-- AC network side faults at busbar $\mathrm{B}_{2}$ in System 1

\section{A. Sudden Load changes}

Figs. 6 and 7 show the obtained results for a load increase and decrease respectively. The switchable load at $\mathrm{B}_{2}$ in Fig.5 which represents $5 \%$ of the pre-transient existing load is introduced and then switched in and out to simulate changes in load.

Figs. 6 presents the response to a total load increase. It is observed in Fig.6(a) that with an increased emulated inertia
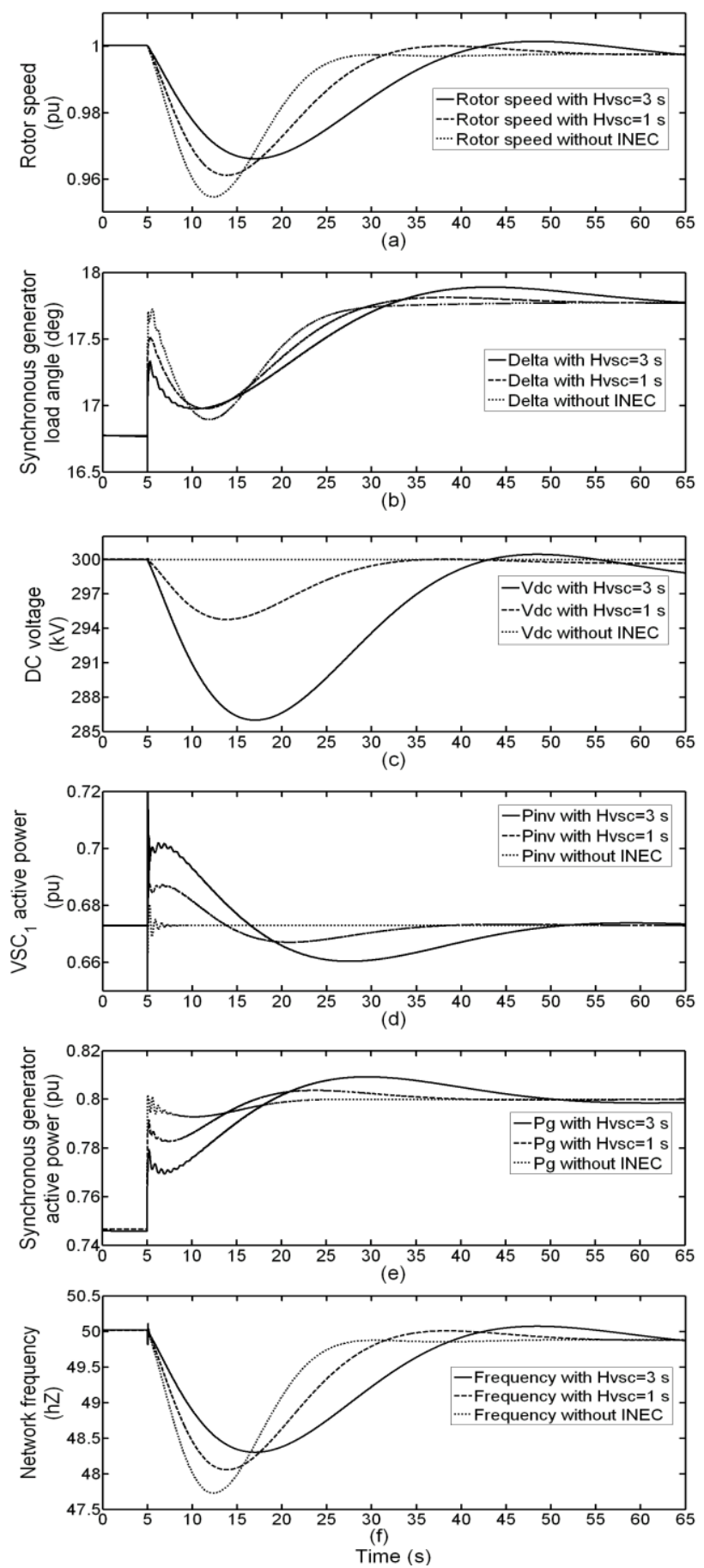

Fig.6. INEC response for 5\% load increase: (a) SG rotor speed; (b) SG load angle (c) HVDC DC link voltage; (d) $\mathrm{VSC}_{1}$ active power; (e) SG active power; (f) Network frequency.

time constant (from the VSC-HVDC), the rate of change of the SG rotor speed is damped, demonstrating that the emulated inertia supplied by the VSC-HVDC improves system stability. The initial SG load angle perturbation, as illustrated in Fig6.(b), is reduced in magnitude as greater amounts of emulated inertia are supplied. The behavior of the SG load angle also shows the stability of the test power system as it settles at a new value following the load increase. Fig.6(c) illustrates that progressively larger values of emulated inertia result in greater variations of the DC link voltage.

This is a postprint of a paper submitted to and accepted for publication in IEEE Transactions on Power Systems [http://dx.doi.org/10.1109/TPWRS.2012.2213101] and is subject to IEEE copyright. 

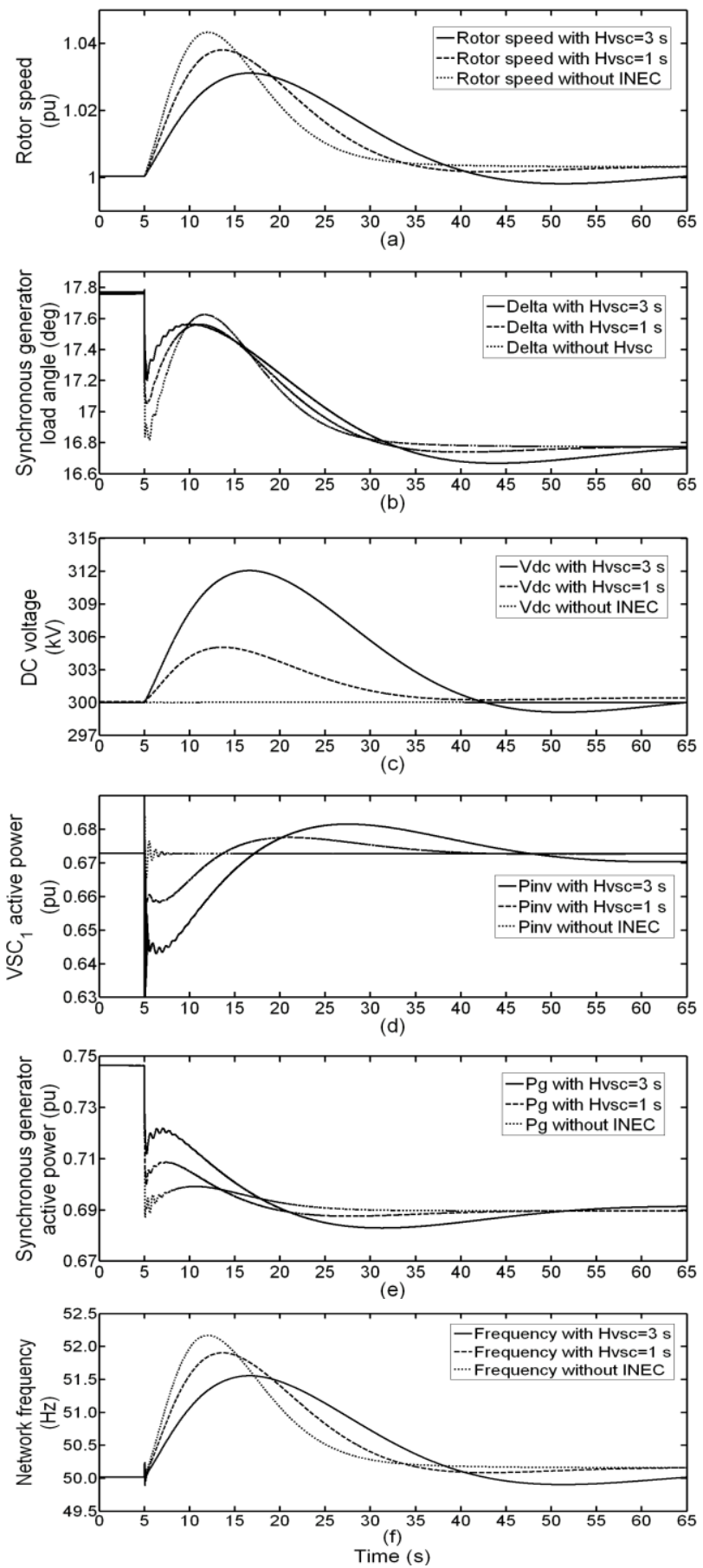

Fig.7. INEC response for 5\% load increase: (a) SG rotor speed; (b) SG load angle (c) HVDC DC link voltage; (d) $\mathrm{VSC}_{1}$ active power; (e) SG active power; (f) Network frequency.

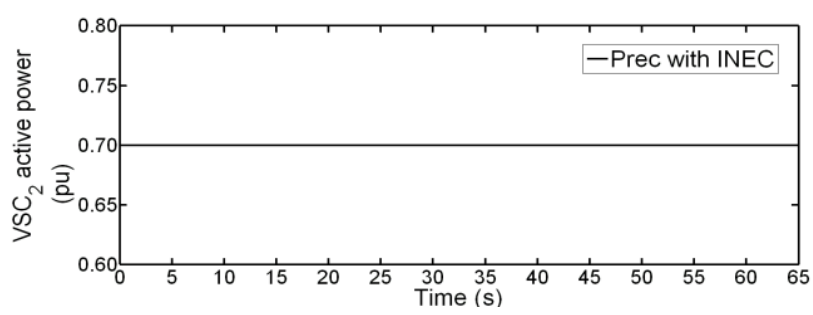

Fig.8. $\mathrm{VSC}_{2}$ active power injected by the offshore wind farm

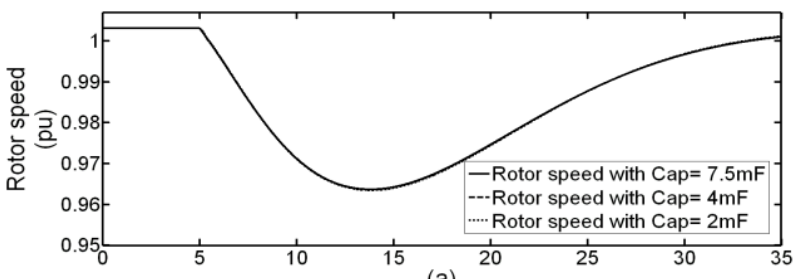

(a)

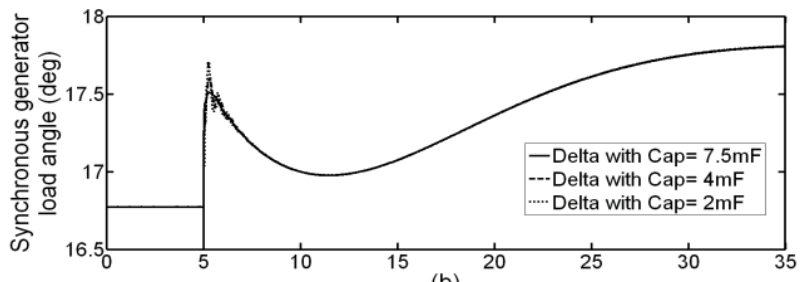

(b)

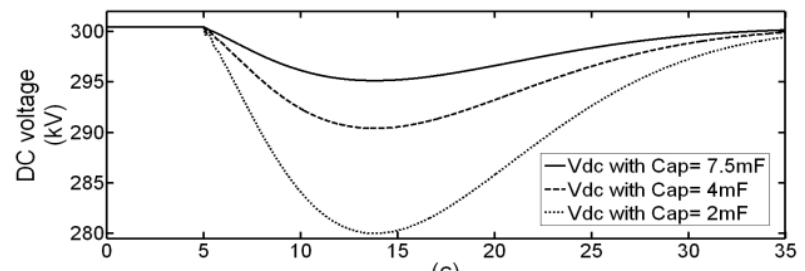

(c)

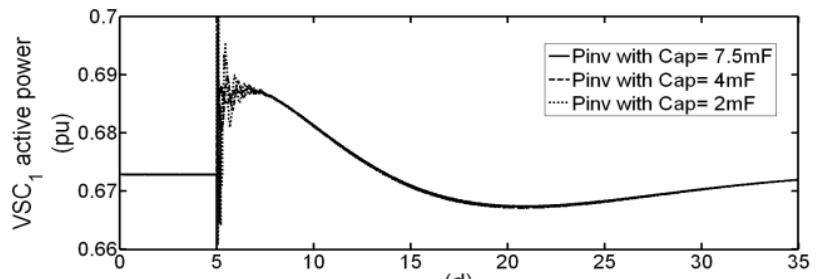

(d)

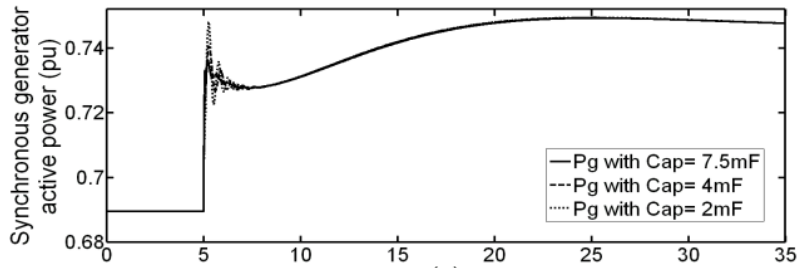

(e)

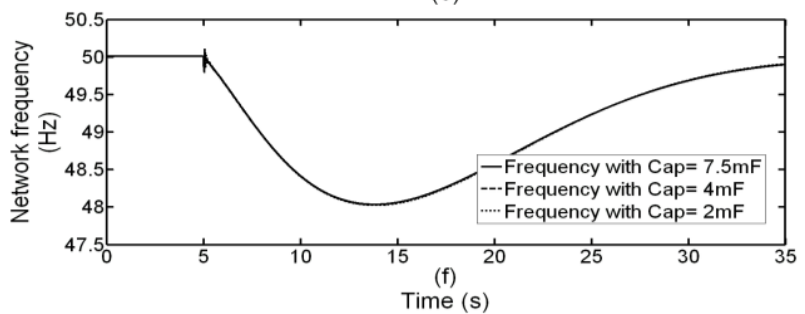

Fig.9. Comparison of different capacitance for the INEC: (a) SG rotor speed; (b) SG load angle (c) HVDC DC link voltage; (d) $\mathrm{VSC}_{1}$ active power; (e) SG active power; (f) Network frequency.

Fig.6(d) shows the active power output from the converter $\mathrm{VSC}_{1}$ during a load increase. The specified inertia constant $\mathrm{H}_{\mathrm{VSC}}$ determines the magnitude and shape of the converter's inertial response. More active power is provided by $\mathrm{VSC}_{1}$ for higher values of $\mathrm{H}_{\mathrm{VSC}}$. This shows how the INEC can provide frequency support. From Fig.6(d) and (e), it is clear that that the $\mathrm{VSC}_{1}$ briefly increases its active power output, until the SG increases its active power to cope with the power mismatch in System 1. Once stable conditions are restored, the converter

This is a postprint of a paper submitted to and accepted for publication in IEEE Transactions on Power Systems [http://dx.doi.org/10.1109/TPWRS.2012.2213101] and is subject to IEEE copyright. 
restores its active power to the original value. Therefore, the INEC enables the VSC-HVDC system to react fast enough to support the primary frequency control. This also reduces the magnitude of the initial transient increase in output power demanded from the SG. Fig.6(f) illustrates the network frequency at $\mathrm{VSC}_{1}$ 's $\mathrm{PCC}$ of $\mathrm{B}_{1}$ and shows in increase in the emulated inertia reduces the frequency transients. This is a potentially very useful benefit of the scheme, and this may become more important if renewable energy replaces conventional generation and especially if significant renewable energy is connected via power electronics.

Figs.7 presents the case of a sudden load reduction, which is simulated by switching out $\mathrm{P}_{\mathrm{L} 2}+\mathrm{Q}_{\mathrm{L} 2}$. It is evident that the INEC scheme successfully damps the rotor speed deviation as presented in Fig.7(a). The magnitude of initial SG load angle perturbations are also significantly reduced due to the action of the INEC scheme, as shown in Fig.7(b). The INEC acts to increase DC link voltage as shown in Fig.7(c), with the capacitors absorbing the excess energy. This results in an instant decrease of the active power output from $\mathrm{VSC}_{1}$ as shown in Fig.7(d), with the response of the SG shown in Fig.7(e). Fig.7(f) shows that increasing the value of $\mathrm{H}_{\mathrm{VSC}}$ reduces the $\mathrm{AC}$ network frequency transients. In all cases, the DC link voltage is maintained within $5 \%(15 \mathrm{kV})$ of the nominal voltage level of $300 \mathrm{kV}$. Increasing the permissible limits on DC voltage (and possibly capacitor ratings) could offer higher emulated inertia.

Fig. 8 shows the active power inputs by $\mathrm{VSC}_{2}$ from the Power System 2 for both cases of the load increase and decrease remain unchanged. It is clear that offshore $\mathrm{VSC}_{2}$ active power input is not affected by the $\mathrm{VSC}_{1}$ active power output variations and the DC capacitor voltage variations. Therefore, the INEC still provides the attractive HVDC attribute of decoupling Systems 1 and 2, avoiding transients in one system propagating through to another system(s). This feature will become more important because of the continuing trend for $\mathrm{AC}$ power systems to interconnect via HVDC especially if sub-sea interconnection is used.

In order to illustrate the impact of DC link capacitor sizing on the INEC performance, difference capacitances for DC capacitors, namely, $\mathrm{C}=7.5 \mathrm{mF}$ (for the base case), $4 \mathrm{mF}$ and $2 \mathrm{mF}$ are used to synthesize the same inertia time constant $\mathrm{H}_{\mathrm{VSC}}=1 \mathrm{~s}$ for the case of 5\% load increase, as seen in Fig.9. These results have shown no differences in the system response for different values of DC link capacitances as evident from $\mathrm{SG}$ rotor speed behaviour in Fig.9(a), SG load angle in Fig.9(b), $\mathrm{VSC}_{1}$ active power output in Fig.9(d), SG active power in Fig.9(e) and network frequency in Fig.9(f). However, it is noticeable that this performance is achieved at the expense of increased DC link voltage variation of the converter $\mathrm{VSC}_{1}$ as the $\mathrm{DC}$ link capacitance reduces. These results indicate that to ensure proper system operation when INEC is implemented in one or more terminals, the DC link capacitance must to be sized taken into account the maximum permissible DC link voltage variation from the rated voltage.
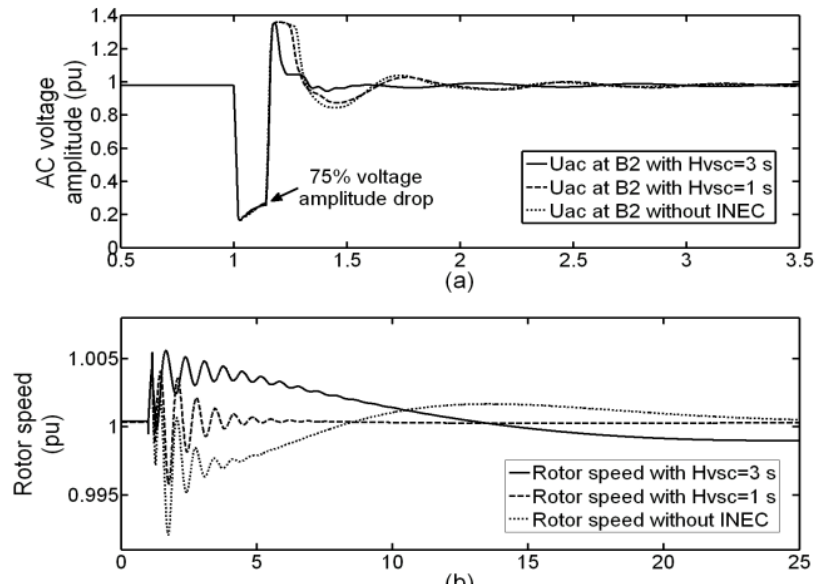

(b)
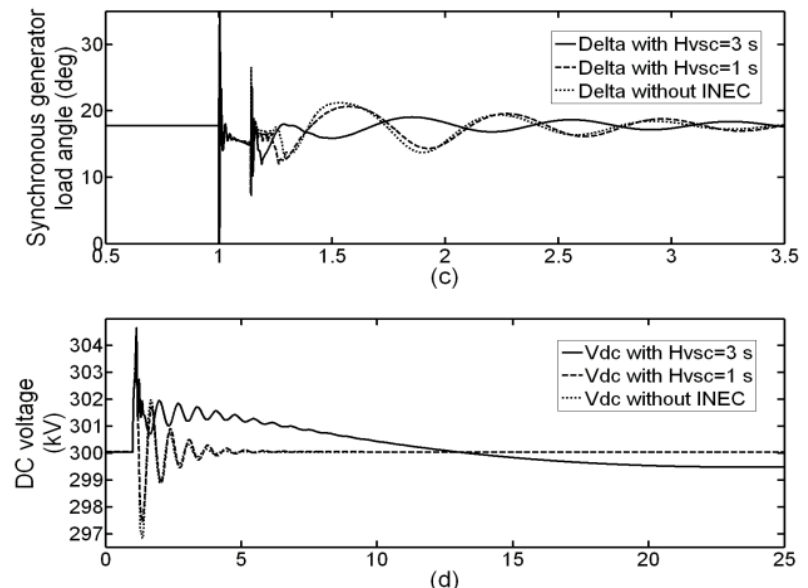

(d)
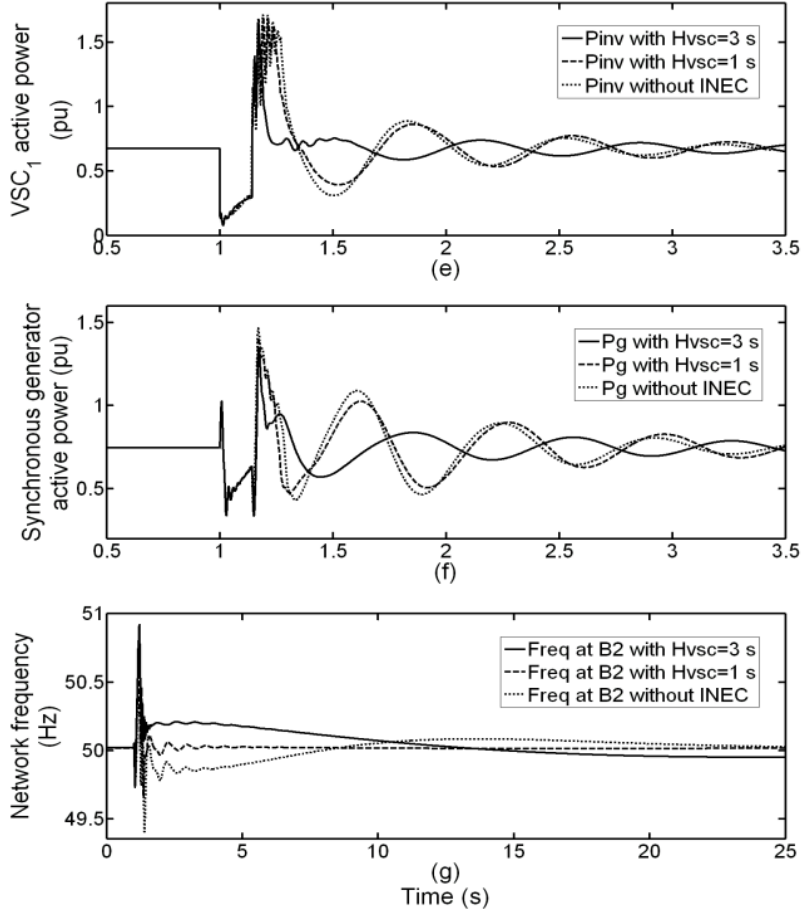

Fig.10. INEC response for 140-ms three-phase-to-ground close fault: (a) zoomed AC voltage amplitude at $\mathrm{B}_{2}$; (b) SG rotor speed; (c) zoomed SG load angle (d) HVDC DC link voltage; (e) zoomed $\mathrm{VSC}_{1}$ active power; (f) zoomed SG active power; (g) Network frequency. 


\section{B. AC faults}

Fig.10 and Fig.11 compare the INEC performance for electrical close and remote faults. In both cases, three-phase faults are initiated at $\mathrm{t}=1 \mathrm{~s}$ and cleared at $\mathrm{t}=1.14 \mathrm{~s}$.

As shown in the zoomed Fig.10(a) the fault results in a $\mathrm{AC}$ voltage amplitude drop of $75 \%$ at busbar $\mathrm{B}_{2}$. Generator rotor speed, with emulated inertia $\mathrm{H}_{\mathrm{VSC}}=3 \mathrm{~s}$, recovers more slowly than for cases with lower values of $\mathrm{H}_{\mathrm{VSC}}$ from the speed increase due to the fault, with relatively lower first and subsequent swing magnitudes, as observed in Fig.10(b). This actually exhibits the electro-mechanical effect of system inertia. Fig.10(c) illustrates the load angle of SG for different values of emulated inertia in the post-fault period. Fig.10(e) presents the $\mathrm{VSC}_{1}$ active power output with and without INEC, which influences behavior throughout each of the three simulation cases. This is directly reflected in Fig.10(f), where the $\mathrm{SG}$ active power output with larger inertia $\mathrm{H}_{\mathrm{VSC}}=3 \mathrm{~s}$ changes less than for cases where $\mathrm{H}_{\mathrm{VSC}}=1 \mathrm{~s}$ and without INEC. During the fault the $\mathrm{VSC}_{1}$ 's current is saturated due to the significant undervoltage therefore the active powers for $\mathrm{HVSC}=3 \mathrm{~s}$, $1 \mathrm{~s}$ and 0 remain the same during this time. It is interesting to see post the fault $\mathrm{VSC}_{1}$ 's active power with larger inertia $\mathrm{H}_{\mathrm{VSC}}=3 \mathrm{~s}$ holds the active power on when the fault is cleared. This can be interpreted by the equal area criterion for SG that the kinectic energy collected by the SG during the fault must be released after the fault, and the reduction on $\mathrm{VSC}_{1}$ 's active power actually facilitates this process. This is important with respect to the first swing stability of a power system. The network frequency at $\mathrm{B}_{2}$ is shown in Fig. $10(\mathrm{~g})$, which obviously has a similar trend to $\mathrm{SG}$ rotor speed.

The effectiveness of INEC strategy in enhancing system stability for distant faults is more obvious, as shown in Fig. 11. The distant fault is represented by a resistive fault applied at $\mathrm{B}_{2}$ leading to a voltage drop of $25 \%$ as shown in zoomed Fig. 11(a). $\mathrm{VSC}_{1}$ 's current output is not saturated due to the relatively smaller voltage drop. It is clear, in the circled region of Fig.11(e), that during the fault (from $\mathrm{t}=1 \mathrm{~s}$ to $1.14 \mathrm{~s}$ ) $\mathrm{VSC}_{1}$ effectively interacts with the network with different active power outputs for different emulated inertia time constants. This leads to different SG load angle and active power output behaviors as shown in Fig.11(c) and Fig.11(f). As illustrated in Fig.11(b) and Fig.11(g) respectively, the SG rotor speed and network frequency drops associated with larger emulated inertia $\mathrm{H}_{\mathrm{VSC}}=3 \mathrm{~s}$ are significantly less than for $\mathrm{H}_{\mathrm{VSC}}=1 \mathrm{~s}$. As observed in Fig.11(d), DC voltage drop for larger values of emulated inertia is higher in order to supply relatively higher values of instantaneous active power as shown in Fig.11(e). It is interesting to see that the network voltage at $\mathrm{B}_{2}$ as shown in Fig.11(a) is also influenced by different values of emulated inertia due to the interactions between $\mathrm{VSC}_{1}$ and the $\mathrm{SG}$.

The AC fault simulation study clearly shows the INEC strategy for VSC-HVDC systems in increasing system fault ride-through capability.
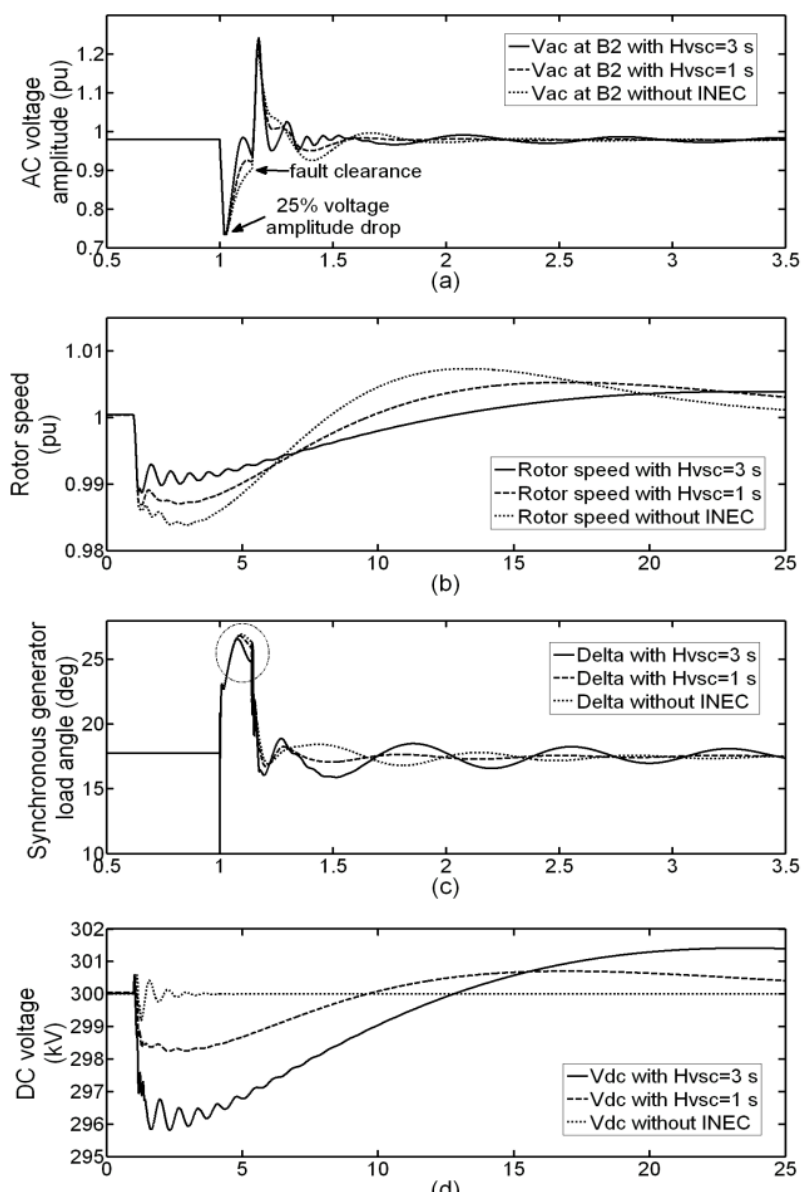

(d)
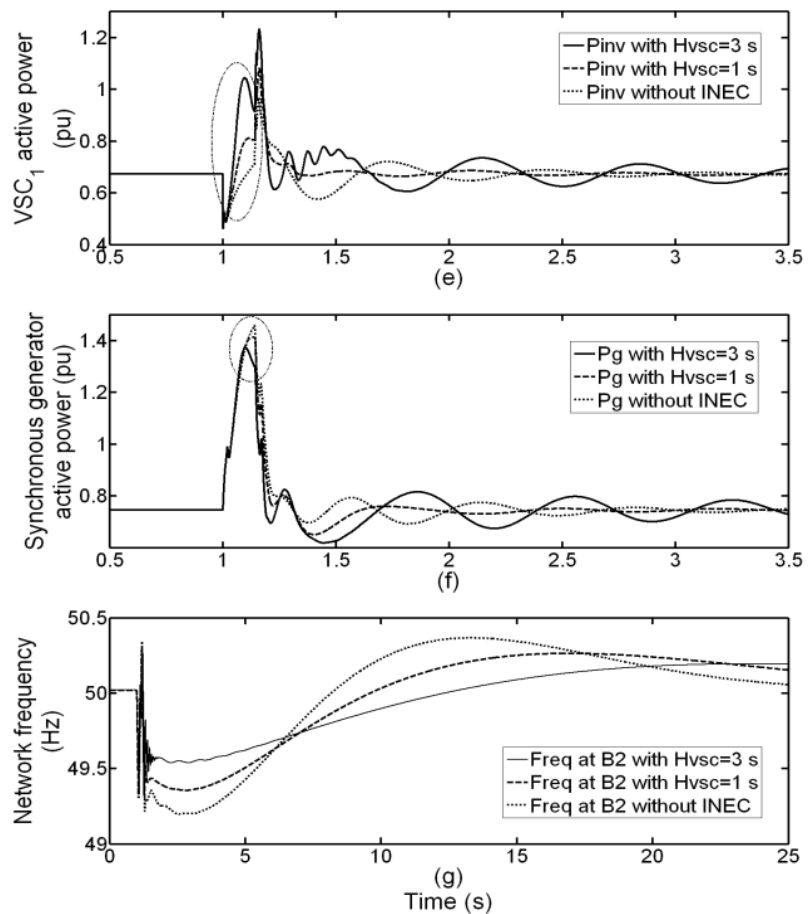

Fig.11. INEC response for 140-ms three-phase-to-ground distant fault: (a) zoomed AC voltage amplitude at $\mathrm{B}_{2}$; (b) SG rotor speed; (c) zoomed SG load angle (d) HVDC DC link voltage; (e) zoomed $\mathrm{VSC}_{1}$ active power; (f) zoomed SG active power; (g) Network frequency.

This is a postprint of a paper submitted to and accepted for publication in IEEE Transactions on Power Systems [http://dx.doi.org/10.1109/TPWRS.2012.2213101] and is subject to IEEE copyright. 


\section{CONCLUSION}

This paper has proposed and evaluated an inertia emulation control (INEC) system for VSC-HVDC transmission systems. INEC employs the electro-static energy stored in the DC capacitors to enable the inverter to provide an inertial response to load and frequency changes in the power system, in a similar fashion to a synchronous generator. The INEC varies the DC voltage to exercise the capacitor energy and the amount of energy exercised varies with the magnitude of the inertia time constants being emulated. INEC possesses the following significant features: (1) Inertia time constants $\mathrm{H}_{\mathrm{VSC}}$ can be specified and varied; (2) DC voltage variations are limited within a specific range; (3) The INEC provided at the inverter terminals of the HVDC links has no impact on the rectifier-side offshore wind power system. Simulations verify that the INEC for VSC-HVDC transmission system is capable of interacting with connected generators, counteracting, and damping generator rotor speed (and system frequency) changes. It allows the VSC-HVDC system to contribute to both the damping of low-frequency oscillations, enhancement of the primary frequency control of the $\mathrm{AC}$ networks and consolidation of system fault ride-through capability. In future, this is likely to become more important due to the continuing trend of HVDC interconnection and also the possible replacement of conventional generation by renewable generation with lower inertia constants.

\section{REFERENCES}

[1] EU Energy Policy to 2050. European Wind Energy Association [Online]. Available:http://www.ewea.org/fileadmin/ewea_documents/documents/ publications/reports/EWEA EU Energy Policy to 2050.pdf

[2] Largest Power Infeed Loss Amendment to GSR007 proposals. GB National Electricity Transmission System Security and Quality of Supply Standard [Online]. Available: http://www.nationalgrid.com/NR/rdonlyres/749C9FD8-1651-4059-8219 -564940C4678C/44473/ReporttoAuthorityfinal.pdf. [Aug. 2011].

[3] Kayikci, M.; Milanovic, J.V.; , "Dynamic Contribution of DFIG-Based Wind Plants to System Frequency Disturbances," IEEE Trans. Power Syst., vol.24, no.2, pp.859-867, May 2009.

[4] Conroy, J.F.; Watson, R.; , "Frequency Response Capability of Full Converter Wind Turbine Generators in Comparison to Conventional Generation," IEEE Trans. Power Syst., vol.23, no.2, pp.649-656, May 2008.

[5] Ingleson, J.W.; Allen, E.; , "Tracking the Eastern Interconnection frequency governing characteristic," 2010 IEEE Power and Energy Society General Meeting, , vol., no., pp.1-6, 25-29 July 2010.

[6] Zhixin Miao; Lingling Fan; Osborn, D.; Yuvarajan, S.; , "Wind Farms With HVdc Delivery in Inertial Response and Primary Frequency Control," IEEE Trans. Energy Convers., vol.25, no.4, pp.1171-1178, Dec. 2010.

[7] Bresesti, P.; Kling, W.L.; Hendriks, R.L.; Vailati, R.; , "HVDC Connection of Offshore Wind Farms to the Transmission System,", IEEE Trans. on Energy Convers., vol.22, no.1, pp.37-43, Mar. 2007.

[8] K. Clark, N. W. Miller, and J. J. Sanchez-Gasca. (2009). "Modeling of GE wind turbine-generators for grid studies," [Online]. Available: http://www.pes-psrc.org/c/C17/GE\%20WTG\%20Modeling-v4\%202.pdf [Aug. 2011]

[9] P. Anderson and A. A. Fouad, Power System Control and Stability. Ames, Iowa, U.S.A: The Iowa State Univerity Press, 1977.

[10] Cuiqing Du, "VSC-HVDC for Industrial Power Systems," Ph.D. dessertation, Dept. Energy and Enviro., Chalmers Univ. of Tech., G" oteborg, Sweden, 2007.
[11] Jiebei Zhu; Booth, C.; , "Future multi-terminal HVDC transmission systems using voltage source converters," Int. Univ. Power Eng. Conf., Cardiff, UK, Sept. 2010, pp.1-6.

[12] MathWorks, "MATLAB Simulink SimPowerSystems blockset," Available: http://www.mathworks.com/ [May 2011].

[13] Bennett, S.; , "Development of the PID controller," IEEE Trans. Control Syst., vol.13, no.6, pp.58-62, 64-5, Dec 1993.

[14] MathWorks, "Hydraulic Turbine and Governor," [Online]. Available: http://www.mathworks.com/ [Aug. 2011].

[15] IEEE Working Group on Prime Mover and Energy Supply Models for System Dynamic Performance Studies, "Hydraulic Turbine and Turbine Control Models for Dynamic Studies," IEEE Trans. Power Syst., Vol.7, No.1, pp. 167-179, February, 1992.

This is a postprint of a paper submitted to and accepted for publication in IEEE Transactions on Power Systems [http://dx.doi.org/10.1109/TPWRS.2012.2213101] and is subject to IEEE copyright. 